\section{Light and gravity: can the full moon really make you go mad?}

\author{
John Launer
}

Earlier human societies attributed great power over human emotions to the moon, just as they did to the movements of other celestial bodies. The words 'lunacy' and 'lunatic' (from the Latin 'luna' for moon) testify to this. The same ideas persist widely today, not only in lay society but among mental health professionals, who often report their impression that patients are more disturbed at the full moon. ${ }^{1}$ Systematic research has generally debunked such ideas, although there has recently been an upsurge in studies claiming that the moon can indeed affect mental health - possibly as a result of tidal effects rather than through variations in moonlight during the month. These studies have been reported more or less uncritically on popular science websites and elsewhere. ${ }^{2}$ What should we now believe?

First, the astronomical facts. The moon has a number of different cycles. It orbits around our planet approximately every 27 days, while rotating on its axis at the same rate, thus keeping only one side visible to us. Our view from earth leads us to believe that its face is waxing and waning in phases during the course of each month but this is an illusion. In reality, the relative angles of sun, moon and earth are changing, so that the lit portion appears to be shrinking and then growing from one full moon to the next - another cycle, which lasts 29.5 days. $^{3}$ Sometimes the full moon appears particularly large, but this is usually an illusion too because it is close to the horizon, making it seem enormous by comparison with objects such as trees and buildings, as well as refracted through the atmosphere. Every 206 days, however, the apparent increase in the moon's size is not an illusion, because its elliptical orbit brings it genuinely as close to us as it will come. This is termed a perigee full moon or, more colloquially, a 'supermoon."

More important in practice than its changing visual appearance, the moon also exerts a gravitational force on the earth. This causes the oceans to bulge more on the side facing the moon than on the far side, leading to a cycle of tides

Correspondence to Dr John Launer, Associate Editor, Postgraduate Medical Journal, London, UK; johnlauner@aol.com that each last around 12.5 hours, so that a lunar tidal day lags behind the solar day by about an hour. When sun and moon are aligned so that their joint gravitational forces are combined, there are particularly high tides or 'spring tides.' These occur twice each lunar month or every 14.8 days. High tides also vary according to the angle of the moon towards our equator, its so-called declination, which has its maximum effect every 13.7 days. These are important matters to mariners who use them to predict tides.

\section{BIOLOGICAL EFFECTS}

In terms of biology, there is no doubt that lunar cycles affect a variety of species either directly, or indirectly through the tides. A survey of such effects appears in a book called 'Moonstruck' by Ernest Naylor, emeritus professor of ocean studies at Bangor University in Wales. ${ }^{5}$ As Naylor points out, life may have begun under the influence of the moon, especially if it originated in tidal regions where the water level fluctuates, rather than in subterranean thermal vents as many believe. Either way, for around 90 per cent of the time that organisms have existed on earth, they have lived in the ocean, the fringes of which are always under the moon's influence. It is not surprising that many creatures therefore possess an internal clock which can be set by lunar-driven tides but then operate semi-independently. One example is a flatworm that comes to the surface of beaches at low tide but burrows back into the sand again just before the tide comes in. These worms display the same rhythm for a while in the laboratory, but it then stops until they are put back on the beach, when the clock soon resets. Naylor's book is full of similar examples, including sea lice that have fortnightly periodicities related to lunar cycles, and a number of creatures like sea urchins, red crabs, grunion fish and turtles, whose reproductive cycles are linked in one way or another either to the visible phases of the moon or its tidal cycles.

The biological facts relating to higher species such as humans, according to Naylor and others, are far less convincing. Even the seemingly obvious association with the human menstrual cycle appears weak. Different primates ovulate at intervals between 10 and 50 days. The human average is 27.3 days (not the lunar light cycle of 29.5), while 80 per cent of women have cycles that are significantly shorter or longer. ${ }^{6}$ There is also no apparent association of lunar phases with ovulation $^{7}$ or childbirth. In relation to mental health, the moon does not have a statistically detectable effect on psychiatric presentations to emergency departments, ${ }^{8}$ suicide attempts ${ }^{9}$ or crime. Naylor's overall conclusion is that 'a connection between the behaviour of mentally ill patients and the Moon, though a longstanding belief, remains a cultural myth and has no scientific standing.' Lunar phases can however affect human sleep patterns: one study showed that sleep time around the full moon can decrease by about $25 \mathrm{~min}$ while cortical reactivity to external stimuli, detected on EEG, is increased in some individuals. ${ }^{10}$

\section{CHALLENGE TO SCIENTIFIC CONSENSUS}

It is the proven effect on sleep that has recently led the US psychiatrist Tom Wehr, now a scientist emeritus at the US National Institute of Mental Health, to challenge the consensus about the moon and mental health. Wehr happened to note that one of his patients with rapidly cycling bipolar disorder had mood cycles with a highly precise and stable periodicity. Ingeniously, Wehr calculated that this appeared to correspond with some multiples of the different kinds of tidal cycle, as well as an additional pattern that matched the 206 day interval between supermoons. ${ }^{11} \mathrm{He}$ formed the hypothesis that the circadian pacemaker in this patient's brain, which would normally be programmed or 'entrained' by sunlight, had somehow been overridden by a lunar gravitational pattern instead. This would cause his natural propensity for sleep to become desynchronised from day and night over the course of several weeks, leading to sudden but regular switches between depression and mania. Since bipolar disorder is known to be sensitive to the timing and duration of sleep ${ }^{12}$ this hypothesis was perhaps not quite as farfetched as it might otherwise seem.

To test this, Wehr examined the records of 16 other patients with the same disorder. He found that some people's mood swings appeared to relate proportionately to a 14.8 day cycle, while others seemed based on a 13.7 cycle - corresponding to the two cycles governing tides. Some patients switched occasionally between the two patterns, or these were 
interrupted by the arrival of supermoons every 206 days. He subsequently published two case reports analysing the long term diaries of two patients with apparently lunar-related cycles. ${ }^{13} 14$ In addition, he and some colleagues have suggested that women's menstrual cycles might after all be governed both by the moon's luminance and its various gravimetric cycles, although modern lifestyles (including artificial light) might have obscured the connection. ${ }^{15}$ Wehr argues that epidemiological studies are consistently failing to detect individual variations that demonstrate how lunar patterns, including gravitational ones, can take over certain people's lives.

Wehr's arithmetic is complex and not always easy to follow. Readers with an appetite for detailed statistical analysis and critical appraisal may want to examine his findings to consider whether or not these are persuasive. His hypothesis is certainly at odds with Naylor's assertion in 'Moonstruck' that 'the gravitational fields of moon and sun are so small that they affect the body only by the weight equivalent of a bead of sweat or a human hair. ${ }^{16}$ If Wehr is correct, he will have opened a window onto an entirely new scientific paradigm. If wrong, he will not have been the first distinguished scientist to have believed in something eccentric and implausible. Only time will tell if his studies have turned the tide of current beliefs, or are pure moonshine.

\section{Twitter John Launer @JohnLauner}

Funding The authors have not declared a specific grant for this research from any funding agency in the public, commercial or not-for-profit sectors.

Competing interests None declared.

Patient consent for publication Not applicable.

Provenance and peer review Not commissioned; internally peer reviewed.

(c) Author(s) (or their employer(s)) 2021. No commercial re-use. See rights and permissions. Published by BMJ.

\section{Check for updates}

To cite Launer J. Postgrad Med J 2021;97:831-832. Published Online First 25 October 2021

Postgrad Med J 2021;97:831-832.

doi:10.1136/postgradmedj-2021-141300

\section{ORCID iD}

John Launer http://orcid.org/0000-0003-3833-9352

\section{REFERENCES}

1 Vance DE. Belief in lunar effects on human behavior. Psychol Rep 1995;76:32-4.

2 BBC Future. The mood altering power of the moon. Available: https://www.bbc.com/future/article/ 20190731-is-the-moon-impacting-your-mood-andwellbeing [Accessed 23 Sep 2021].

3 NASA Science. Earth's moon. Available: https:// moon.nasa.gov/inside-and-out/top-moon-questions/ [Accessed 23 Sep 2021].
4 EarthSky: How the earth's orbit makes supermoons. Available: https://earthsky.org/astronomy-essentials/ extra-close-perigees-extra-far-apogees-new-and-fullmoons/ [Accessed 23 Sep 2021].

5 Naylor E. Moonstruck. Oxford: Oxford University Press, 2015.

6 Cutler WB. Lunar and menstrual phase locking. Am J Obstet Gynecol 1980:137:834-9.

7 Komada Y, Sato M, Ikeda Y, et al. The relationship between the lunar phase, menstrual cycle onset and subjective sleep quality among women of reproductive age. Int J Environ Res Public Health 2021;:18:3245

8 Francis OJ, Kopke BJ, Affatato AJ, et al. Psychiatric presentations during all 4 phases of the lunar cycle. Adv Mind Body Med 2017;31:4-7.

9 Maldonado G, Kraus JF. Variation in suicide occurrence by time of day, day of the week, month, and lunar phase. Suicide Life Threat Behav 1991;21:174-87.

10 Smith M, Croy I, Persson Waye K. Human sleep and cortical reactivity are influenced by lunar phase. Curr Biol 2014;24:R551-2.

11 Wehr TA. Bipolar mood cycles and lunar tidal cycles. Mol Psychiatry 2018;23:923-31.

12 Wehr TA, Turner EH, Shimada JM, et al. Treatment of rapidly cycling bipolar patient by using extended bed rest and darkness to stabilize the timing and duration of sleep. Biol Psychiatry 1998:43:822-8.

13 Avery DH, Wehr TA. Synchrony of sleep-wake cycles with lunar tidal cycles in a rapid-cycling bipolar patient. Bipolar Disord 2018;20:399-402.

14 Wehr TA. Bipolar mood cycles associated with lunar entrainment of a circadian rhythm. Trans/ Psychiatry 2018;8:151.

15 Helfrich-Förster C, Monecke S, Spiousas I, et al. Women temporarily synchronize their menstrual cycles with the luminance and gravimetric cycles of the moon. Sci Adv 2021;7:eabe1358.

16 Naylor E. Moonstruck. Oxford: Oxford University Press, 2015: 198. 